\title{
A New Synthetic Route to (Trifluoromethyl)quinolines: Nickel- Catalyzed Insertion of an Alkyne into an Aromatic C-S Bond by Formation of a Thianickelacycle and Thermal Desulfidation
}

\author{
Tasuku Inami \\ Takuya Kurahashi* (D) \\ Seijiro Matsubara*(D) \\ Department of Material Chemistry, School of Engineering, \\ Kyoto University, Kyoto 615-8510, Japan \\ kurahashi.takuya.2c@kyoto-u.ac.jp \\ matsubara.seijiro.2e@kyoto-u.ac.jp
}

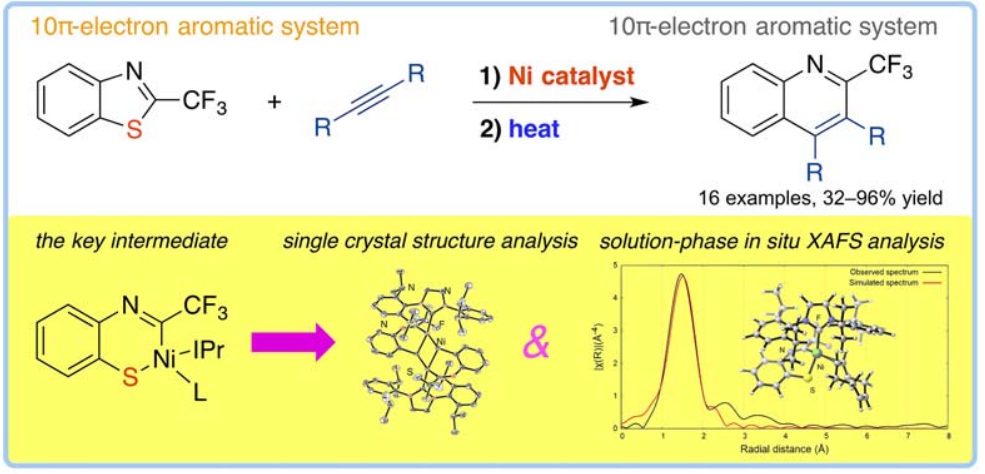

Received: 30.08 .2021

Accepted after revision: 13.09 .202

Published online: 05.10 .2021

DOI: 10.1055/s-0037-1610785; Art ID: st-2021-u0309-|

Abstract We have developed a nickel-catalyzed insertion reaction of an alkyne into a 2-(trifluoromethyl)-1,3-benzothiazole to give a sevenmembered benzothiazepine that is converted into a 2-(trifluoromethyl)quinoline by thermal desulfidation. This process can be considered a formal substitution of a sulfur atom with an alkyne. The structure of the thianickelacycle intermediate formed through oxidative addition of a C$S$ bond in the benzothiazole to nickel( 0 ) was confirmed by $\mathrm{X}$-ray singlecrystal structure analysis and in situ X-ray absorption fine-structure spectroscopy

Key words nickel catalysis, cycloaddition, desulfidation, alkynes, benzothiazoles, trifluoromethylquinolines

The quinoline skeleton appears in a variety of natural products, especially alkaloids, and is widely used in the design of many pharmaceuticals. In particular, fluorine-containing quinolines, such as 2-(trifluoromethyl)quinoline, have been attracting significant interest, because the fluorine atoms play a pivotal role in bioactivity and they provide a further utility for structural elaboration. ${ }^{1}$ For example, the antiprotozoal agent mefloquine, which has a 2-(trifluoromethyl)quinoline skeleton, is one of the main drugs currently used in the treatment of malaria. Therefore, we expected that the development of new methods for the synthesis of trifluoromethyl-substituted quinolines would be important and might involve a nickel-catalyzed insertion reaction. Here, we report a nickel-catalyzed insertion reaction of an alkyne with 2-(trifluoromethyl)-1,3-benzothiazoles through the cleavage of the $\mathrm{C}-\mathrm{S}$ bond in the aromatic thiazole ring to afford a seven-membered benzothiazepine that gives a 2-(trifluoromethyl)quinoline through facile thermal elimination of the sulfur atom. Various types of carbothiolation of $\mathrm{C}-\mathrm{C}$ unsaturated bonds with various transition-metal catalysts have previously been studied but, to the best of our knowledge, transition-metal-catalyzed carbothiolation with sulfur-containing aromatic compounds has not been widely studied. ${ }^{2-4}$

We initially examined the reaction of 2-(trifluoromethyl)-1,3-benzothiazole (1a) with oct-4-yne (2a) in the presence of $10 \mathrm{~mol} \%$ of $\left[\mathrm{Ni}(\mathrm{cod})_{2}\right]$ and 1,3-bis(2,6-diisopropylphenyl)imidazol-2-ylidene (IPr) in hexane at $25{ }^{\circ} \mathrm{C}$ for 12 hours (Scheme 1 ). The reaction gave the 2 -(trifluoromethyl)benzothiazepine 3aa in 38\% yield, along with the 2-(trifluoromethyl)quinoline 4aa in $8 \%$ yield through the elimination of the sulfur atom. Notably, the starting benzothiazole 1a is readily available through the condensation reaction of 2-aminobenzenethiol with trifluoroacetic anhydride. When our reaction was performed at $80{ }^{\circ} \mathrm{C}$, 4aa was obtained as the sole product in $12 \%$ yield. Further examination revealed that the yield of 4 aa improved to $50 \%$ when the reaction was performed initially at $25{ }^{\circ} \mathrm{C}$ for 12 hours and then at $80^{\circ} \mathrm{C}$ for three hours.

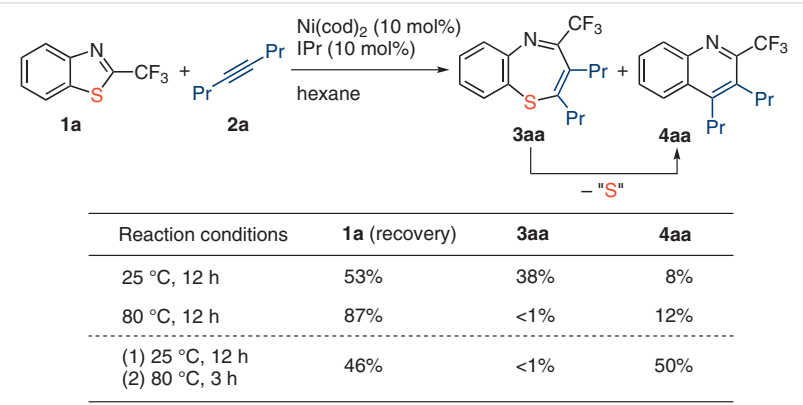

Scheme 1 Nickel-catalyzed reaction and thermal desulfidation 
To investigate this insertion-elimination process of an alkyne and sulfur atom in detail, we next examined the reaction conditions. The results of our attempts to optimize the reaction conditions are summarized in Table 1 . Phosphine ligands were not effective for this insertion reaction (Table1, entries 1-4); however, with IPr, quinoline 4aa was obtained in moderate yield after elimination of the sulfur atom (entry 5). The yield increased slightly when the amount of IPr was increased to $20 \mathrm{~mol} \%$ (entry 6). On increasing the concentration of $1 \mathbf{a}$ to $0.67 \mathrm{M}$, 4aa was obtained in almost quantitative yield (entry 7 ). We confirmed that this reaction does not proceed in the absence of the $\mathrm{Ni}$ precatalyst (entry 8). Neither 2-methyl-1,3-benzothiazole nor 2-phenyl-1,3-benzothiazole reacted with 2a, even under more severe conditions (e.g., in toluene at $130{ }^{\circ} \mathrm{C}$ ), and neither the corresponding benzothiazepine 3 nor the quinoline 4 was obtained. These results suggest that the presence of a trifluoromethyl group at the C2 position of substrate $\mathbf{1}$ is essential for this transformation. The trifluoromethyl group might contribute to an acceleration of oxidative addition and/or insertion of an alkyne in the nickel-catalyzed reaction. Of note, the presence of other functional groups, such as $\mathrm{F}$ or $\mathrm{MeO}$, in the benzothiazole did not promote the cycloaddition. ${ }^{4}$

With the optimized reaction conditions, we carried out the nickel-catalyzed reactions of various 2-(trifluoromethyl)benzothiazoles $\mathbf{1}$ and alkynes $\mathbf{2}$ to examine the scope of the transformation to form 2-(trifluoromethyl)quinolines 4 (Scheme 2). Hex-3-yne (2b) and dodec-6-yne (2c) reacted smoothly with benzothiazole 1a to give the corresponding

Table 1 Reaction Conditions for the Insertion Reaction and Elimination ${ }^{\text {a }}$

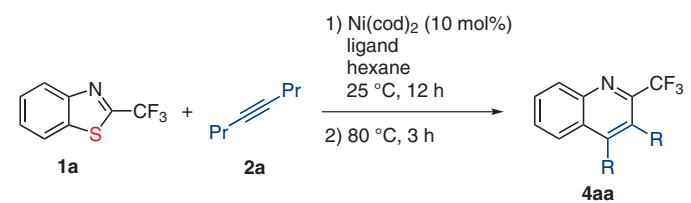

\begin{tabular}{llll}
\hline Entry & Ligand (mol\%) & 1a (M) & Yield $^{\mathrm{b}}(\%)$ \\
\hline 1 & $\mathrm{PMe}_{3}(20)$ & 0.2 & 0 \\
2 & $\operatorname{PPr}_{3}(20)$ & 0.2 & 4 \\
3 & $\mathrm{PCy}_{3}(20)$ & 0.2 & 8 \\
4 & $\operatorname{PPh}_{3}(20)$ & 0.2 & 5 \\
5 & $\operatorname{Pr}(10)$ & 0.2 & 50 \\
6 & $\operatorname{Pr}(20)$ & 0.2 & 66 \\
7 & $\operatorname{Pr}(20)$ & 0.67 & $96(94)^{\mathrm{c}}$ \\
$8^{e}$ & $\operatorname{IPr}(20)$ & 0.67 & 0 \\
\hline
\end{tabular}

a Reaction conditions; $1 \mathrm{a}(0.2 \mathrm{mmol}), 2 \mathrm{a}(0.4 \mathrm{mmol}),\left[\mathrm{Ni}(\mathrm{cod})_{2}\right](0.02$ mmol), ligand, hexane, $25^{\circ} \mathrm{C}, 12 \mathrm{~h}$, then $80^{\circ} \mathrm{C} 3 \mathrm{~h}$.

${ }^{b}$ Determined by ${ }^{19} \mathrm{~F}$ NMR.

'Isolated yield.

e Without $\left[\mathrm{Ni}(\operatorname{cod})_{2}\right]$.
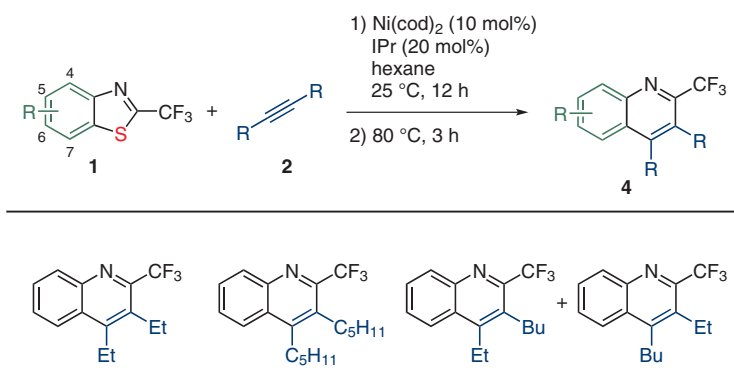

4ab; $83 \%$ 4ac; $90 \%$ 4ad; $90 \%(59 / 49)^{\mathrm{a}}$

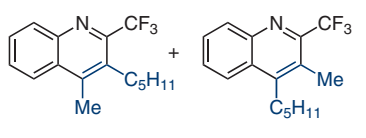
4ae; $84 \%(71 / 29)^{\mathrm{a}}$

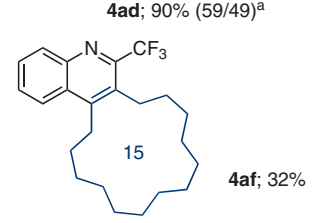<smiles>COCCCc1c(C(F)(F)F)nc2ccccc2c1CCCOC</smiles>

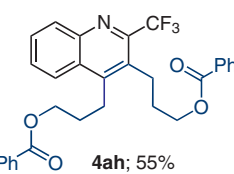

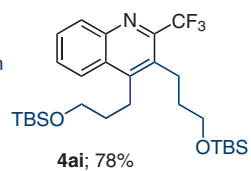

4ag; $90 \%$ ${ }_{\mathrm{Ph}}$ 人ah; $55 \%$<smiles>CCCc1c(C(F)(F)F)nc2ccc(I)cc2c1CC</smiles><smiles>CCCc1c(C(F)(F)F)nc2ccc(OC)cc2c1C(F)(F)F</smiles><smiles>CCCc1c(C(F)(F)F)nc2ccc(C(F)(F)F)cc2c1C(F)(F)F</smiles>
4ca; $78 \%$<smiles>CCCc1c(C(F)(F)F)nc2ccc(Cl)cc2c1[18O]</smiles><smiles>CCCC(C)(C)c1c(C(F)(F)F)nc2c([N+](=O)[O-])cccc2c1C(=O)O</smiles>
4da; $79 \%$

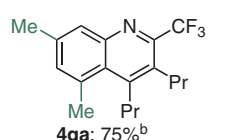

4ga; $75 \%^{\mathrm{b}}$

Scheme 2 Substrate scope. Isolated yields are reported. ${ }^{\text {a Ratio of re- }}$ gioisomers. ${ }^{\mathrm{b}}$ Reaction temperature: $25^{\circ} \mathrm{C}(12 \mathrm{~h})$, then $100{ }^{\circ} \mathrm{C}(6 \mathrm{~h})$.

quinolines 4ab and 4ac in high yields of 83 and 90\%, respectively. Unsymmetrically substituted alkynes afforded regioisomeric mixtures of quinolines in high yields (4ad, 90\%; 4ae, 84\%). Cyclopentadecyne also participated in the reaction to give the corresponding product 4af, albeit in low yield (32\%). Ether, ester, and siloxy functional groups were tolerated in the reaction, giving moderate-to-good yields (4ag, 90\%; 4ah, 55\%; 4ai, 78\%). However, diaryl-substituted alkynes, such as diphenylethyne, and terminal alkynes, such as oct-1-yne, did not give the desired products, and 1a was fully recovered. The reaction of $\mathbf{1 a}$ with sterically bulky triisopropylsilyl- or tert-butyl-substituted alkynes did not give the corresponding cycloadducts. The reaction is therefore sensitive toward steric effects of substituents on the alkyne. The effect of substituents on $\mathbf{1}$ was also investigated. Electron-donating or electron-withdrawing groups at the $\mathrm{C} 6$ position had a negligible effect on the reactivity (4ba, 96\%; 4ca, 78\%). A chloro group at the $\mathrm{C} 6$ position was tolerated under the reaction conditions, and the corresponding 2-(trifluoromethyl)quinoline 4da was obtained in $79 \%$ yield. The reaction of benzothiazoles bearing a methyl group at the $\mathrm{C} 6$ or $\mathrm{C} 4$ position with alkyne $\mathbf{2 a}$ gave the corresponding quinolines (4ea; 92\%, 4fa; 67\%). 5,7-Dimethyl- 
2-(trifluoromethyl)-1,3-benzothiazole $\mathbf{1 g}$ reacted with $\mathbf{2 a}$ to afford quinoline $4 \mathrm{ga}$ in $75 \%$ yield. Notably, a higher reaction temperature $\left(100{ }^{\circ} \mathrm{C}\right)$ and a prolonged reaction time $(6$ $\mathrm{h}$ ) for the elimination of the sulfur atom were required to afford 4ga.

From this result, we found that the reaction of benzothiazole $\mathbf{1 g}$ with $\mathbf{2 a}$ afforded the thermally stable seven-membered benzothiazepine 3ga as the sole product in 73\% isolated yield (Scheme 3). Steric repulsive effects of the substituents on 3ga effectively prevented the elimination of the sulfur atom. ${ }^{5,6}$ When $3 g a$ was heated at $100{ }^{\circ} \mathrm{C}$, the corresponding 2-(trifluoromethyl)quinoline 4ga was obtained in almost quantitative yield through elimination of the sulfur atom. These results clearly indicate that (a) the nickelcatalyzed reaction of benzothiazole $\mathbf{1}$ with alkyne $\mathbf{2}$ affords benzothiazepine $\mathbf{3}$, and (2) subsequent thermal desulfidation of 3 gives quinoline 4 .

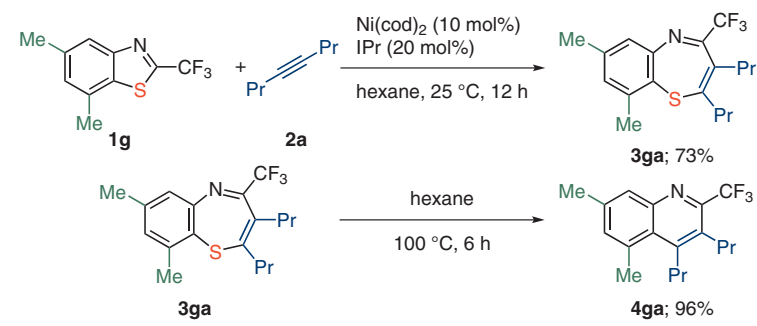

Scheme 3 Stepwise process: nickel-catalyzed insertion reaction of an alkyne and thermal elimination of sulfur atom.

To elucidate the mechanism underlying the nickel-catalyzed reaction, we performed a stoichiometric reaction of benzothiazole 1a with the nickel $(0)$ catalyst (Scheme $4 a$ ). When equimolar amounts of $\mathbf{1 a},\left[\mathrm{Ni}(\mathrm{cod})_{2}\right]$, and $\mathrm{IPr}$ were reacted in hexane at room temperature, a precipitate formed immediately and was collected by filtration after 30 minutes. A high-quality crystal, suitable for X-ray single-crystal analysis, was obtained by crystallization from toluene at $-30{ }^{\circ} \mathrm{C}$, and the structure of the product was unambiguously confirmed to be that of the thianickelacycle dimer $\mathbf{5 a}$ (dimer) (Figure 1). ${ }^{7}$ Treatment of $\mathbf{5 a}$ (dimer) with alkyne $\mathbf{2 a}$ in toluene at room temperature for 12 hours and then at $80^{\circ} \mathrm{C}$ for three hours resulted in quantitative formation of quinoline 4aa (Scheme 4b).

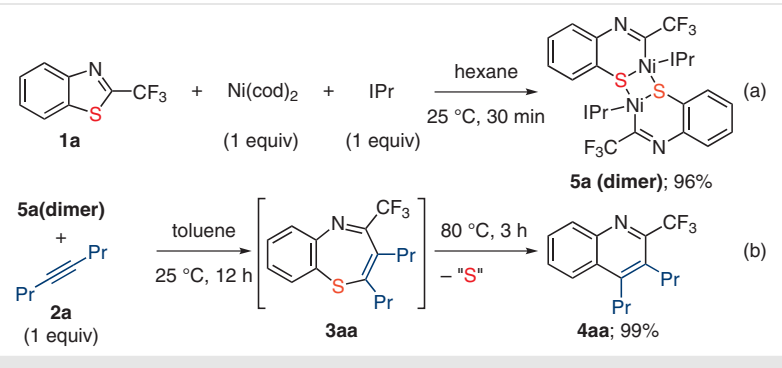

Scheme 4 Stoichiometric reactions
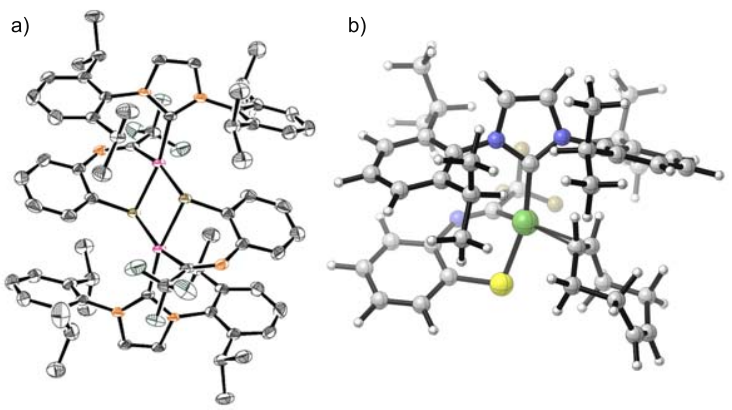

Figure 1 (a) ORTEP drawing of 5a(dimer). (b) DFT-calculated structure of cyclooctadiene-coordinated thianickelacycle 5 a (monomeric complex).

To gain insight into the formation of the monomeric thianickelacycle $\mathbf{5 a}$ in the solution phase, we conducted an in situ X-ray absorption fine-structure (XAFS) spectroscopic study of the stoichiometric reaction of $\left[\mathrm{Ni}(\operatorname{cod})_{2}\right]$ ( 1 equiv) and $\operatorname{IPr}$ (1equiv) with 1a in toluene (Figure 2). The fit of $\mathrm{Ni}$ $K$-edge EXAFS spectrum was performed with cyclooctadiene-coordinated thianickelacycle 5a (Figure 1b). The spectral features arising from the coordination sphere of the nickel atoms matched the spectra simulated by using the DFT-calculated structure of complex $\mathbf{5 a}\left(R_{\mathrm{factor}}=1.7 \%\right)$. The structural results obtained from the EXAFS analysis were in good agreement, confirming that nickel(0) catalyst reacts with $1 \mathbf{a}$ to afford $\mathbf{5 a}$ as a monomeric thianickelacycle.

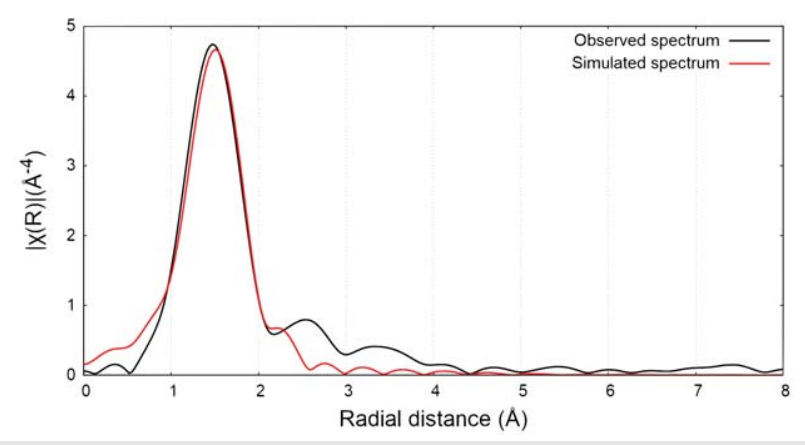

Figure 2 Solution-phase Ni K-edge EXAFS analysis [Fourier transform of the $k_{3}$-weighted spectrum: experimental spectrum (black line) and FEFF-calculated fitting of DFT model $5 a$ (red line), $R_{\text {factor }}=1.7 \%$ ]

On the basis of the formation of the seven-membered benzothiazepine and the thermal elimination of the sulfur atom (Scheme 3), as well as the results of the stoichiometric reaction with the nickel complex (Scheme 4) and the in situ $\mathrm{X}$-ray absorption fine-structure analysis (Figures 1 and 2), we propose the plausible reaction mechanism shown in Scheme $5{ }^{7}$ As the first step, oxidative addition of the C-S bond of benzothiazole 1a to the nickel $(0)$ complex occurs to afford thianickelacycle 5a. Subsequent coordination of alkyne $\mathbf{2 a}$ to the resulting nickel complex and migratory in- 
sertion affords thianickelacycle 7aa. Reductive elimination then gives benzothiazepine 3aa, with regeneration of the nickel(0) catalyst. Finally, 3aa is converted into quinoline 4aa by thermal elimination of the sulfur atom through a pericyclic reaction.

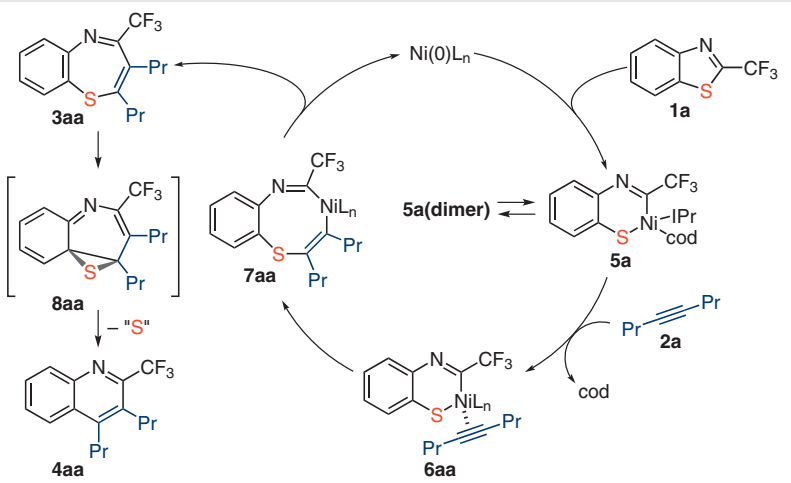

Scheme 5 Plausible reaction mechanism

In conclusion, we have developed a nickel-catalyzed insertion reaction of an alkyne into a $\mathrm{C}-\mathrm{S}$ bond of benzothiazole to give benzothiazepine derivative, which can be thermally converted into a quinoline through facile elimination of the sulfur atom. ${ }^{8}$ Overall, the reaction process provides an unconventional entry to the (trifluorometh$\mathrm{yl}$ )quinoline ring system, which is an important fluorinated heterocyclic moiety in pharmaceutical chemistry. Furthermore, we successfully confirmed that a thianickelacycle is formed through oxidative addition of the $\mathrm{C}-\mathrm{S}$ bond of the aromatic heterocycle to nickel(0). Further studies on expanding the substrate scope are ongoing in our laboratories, and the results will be reported in due course.

\section{Conflict of Interest}

The authors declare no conflict of interest.

\section{Funding Information}

This work was supported by Grants-in-Aid for Scientific Research (Nos. 20H02737, 18H04253 and 17KT0006) from the Ministry of Education, Culture, Sports, Science and Technology (Japan).

\section{Acknowledgment}

We thank Dr. Hiroyasu Sato (Rigaku) for his valuable help in the X-ray crystal structural analysis. We also thank Drs. Tetsuo Honma and Dr. Hironori Ofuchi (JASRI: Japan Synchrotron Radiation Research Institute), and Mr. Kyohei Fujiwara (Ajinomoto Co., Inc.) for their valuable help with X-ray absorption fine-structure analysis. A portion of this study was performed at the BL14B2 beamline of the SPring- 8 synchrotron radiation facility with the approval of the Japan Synchrotron
Radiation Research Institute (Proposals 2019A1712, 2019B1842, 2020A1624, 2020A1766, and 2021B1720).

\section{Supporting Information}

Supporting information for this article is available online at https://doi.org/10.1055/s-0037-1610785.

\section{References and Notes}

(1) (a) Amii, H.; Kishikawa, Y.; Uneyama, K. Org. Lett. 2001, 3, 1109. (b) Chen, Z.; Zhu, J.; Xie, H.; Li, S.; Wu, Y.; Gong, Y. Chem. Commun. 2010, 46, 2145. (c) Han, J.; Cao, L.; Bian, L.; Chen, J.; Deng, H.; Shao, M.; Jin, Z.; Zhang, H.; Cao, W. Adv. Synth. Catal. 2013, 355, 1345. (d) Li, Y.; Zhang, L.; Zhan, L.; Wu, Y.; Gong, Y. Org. Biomol. Chem. 2013, 11, 7267. (e) Linderman, R. J.; Kirollos, K. S. Tetrahedron Lett. 1990, 31, 2689. (f) Han, J.; Li, L.; Shen, Y.; Chen, J.; Deng, H.; Shao, M.; Lu, X.; Zhang, H.; Cao, W. Eur. J. Org. Chem. 2013, 8323. (g) Chen, Y.; Huang, J.; Hwang, T.-L.; Li, T. J.; Cui, S.; Chan, J.; Bio, M. Tetrahedron Lett. 2012, 53, 3237. (h) Dong, X.; Xu, Y.; Liu, J. J.; Hu, Y.; Xiao, T.; Zhou, L. Chem. Eur. J. 2013, 19, 16928. (i) Li, S.; Yuan, Y.; Zhu, J.; Xie, H.; Chen, Z.; Wu, Y. Adv. Synth. Catal. 2010, 352, 1582. (j) Sloop, H. C.; Bumgardner, C. L.; Loehle, W. D. J. Fluorine Chem. 2002, 118, 135. (k) Keller, H.; Schlosser, M. Tetrahedron 1996, 52, 4637. (1) Braznenok, I. L.; Nenajdenko, V. G.; Balenkova, E. S. Eur. J. Org. Chem. 1999, 937. (m) Zhu, M.; Wang, Z.; Xu, F.; Yu, J.; Fu, W. J. Fluorine Chem. 2013, 156, 21. (n) Zhu, M.; Fu, W.; Zou, G.; Xun, C.; Deng, D.; Ji, B. J. Fluorine Chem. 2012, 135, 195. (o) El Kharrat, S.; Skander, M.; Dahmani, A.; Laurent, P.; Blancou, H. J. Org. Chem. 2005, 70, 8327.

(2) (a) Hua, R.; Takeda, H.; Onozawa, S.-y.; Abe, Y.; Tanaka, M.J. Am. Chem. Soc. 2001, 123, 2899. (b) Sugoh, K.; Kuhiyasu, H.; Sugae, T.; Ohtaka, A.; Takai, Y.; Tanaka, A.; Machino, C.; Kambe, N.; Kurosawa, H. J. Am. Chem. Soc. 2001, 123, 5108. (c) Kuniyasu, H.; Kurosawa, H. Chem. Eur. J. 2002, 8, 2660. (d) Hirai, T.; Kuniyasu, H.; Kambe, N. Chem. Lett. 2004, 33, 1148. (e) Hirai, T.; Kuniyasu, H.; Asano, S.; Terao, J.; Kambe, N. Synlett 2005, 1161. (f) Kuniyasu, H.; Kambe, N. Chem. Lett. 2006, 35, 1320. (g) Kamiya, I.; Kawakami, J.-i.; Yano, S.; Nomoto, A.; Ogawa, A. Organometallics 2006, 25, 3562. (h) Yamashita, F.; Kuniyasu, H.; Terao, J.; Kambe, N. Org. Lett. 2008, 10, 101. (i) Minami, Y.; Kuniyasu, H.; Kambe, N. Org. Lett. 2008, 10, 2469. (j) Wang, M.; Cheng, L.; Wu, A. Dalton Trans. 2008, 3879. (k) Toyofuku, M.; Fujiwara, S.-i.; Shin-ike, T.; Kuniyasu, H.; Kambe, N. J. Am. Chem. Soc. 2008, 130, 10504. (1) Minami, Y.; Kuniyasu, H.; Miyafuji, K.; Kambe, N. Chem. Commun. 2009, 3080. (m) Minami, Y.; Kuniyasu, H.; Sanagawa, A.; Kambe, N. Org. Lett. 2010, 12, 3744. (n) Fujiwara, K.; Kurahashi, T.; Matsubara, S. Org. Lett. 2010, 12, 4548. (o) Ozaki, T.; Nomoto, A.; Kamiya, I.; Kawakami, J.-i.; Ogawa, A. Bull. Chem. Soc. Jpn. 2011, 84, 155. (p) Fujiwara, K.; Kurahashi, T.; Matsubara, S. Chem. Lett. 2011, 40, 322. (q) Arisawa, M.; Igarashi, Y.; Tagami, Y.; Yamaguchi, M.; Kabuto, C. Tetrahedron Lett. 2011, 52, 920. (r) Ochi, Y.; Kurahashi, T.; Matsubara, S. Org. Lett. 2011, 13, 1374. (s) Inami, T.; Baba, Y.; Kurahashi, T.; Matsubara, S. Org. Lett. 2011, 13, 1912. (t) Iwasaki, M.; Fujino, D.; Wada, T.; Kondoh, A.; Yorimitsu, H.; Oshima, K. Chem. Asian J. 2011, 6, 3190. (u) Hooper, J. F.; Chaplin, A. B.; González-Rodríguez, C.; Thompson, A. L.; Weller, A. S.; Willis, M. C. J. Am. Chem. Soc. 2012, 134, 2906. (v) Nishi, M.; Kuninobu, Y.; Takai, K. Org. Lett. 2012, 14, 6116. 
(w) Arambasic, M.; Hooper, J. F.; Willis, M. C. Org. Lett. 2013, 15, 5162. (x) Inami, T.; Kurahashi, T.; Matsubara, S. Org. Lett. 2014, 16, 5660. (y) Nakamaura, I.; Sato, T.; Yamamoto, Y. Angew. Chem. Int. Ed. 2006, 45, 4473. (z) Shibata, T.; Sekine, A.; Akino, M.; Ito, M. Chem. Commun. 2021, 57, 9048.

(3) For cleavage of the C-S bonds of thiophene or thiazole derivatives by a stoichiometric amount of transition-metal complexes, see: (a) Sánchez-Delgado, R. A. Organometallic Modeling of the Hydrodesulphurization and Hydrodenitrogenation Reactions; Springer: Dordrecht, 2002. For selected examples, see: (b) Jones, W. D.; Dong, L. J. Am. Chem. Soc. 1991, 113, 559. (c) Morikita, T.; Hirano, M.; Sasaki, A.; Komiya, S. Inorg. Chim. Acta 1991, 291, 341. (d) Jones, W. D.; Chin, R. M. Organometallics 1992, 11, 2698. (e) Vicic, D. A.; Jones, W. D. J. Am. Chem. Soc. 1997, 119, 10855. (f) Churchill, D. G.; Bridgewater, B. M.; Parkin, G. J. Am. Chem. Soc. 2000, 122, 178. (g) Chantson, J.; Görls, H.; Lotz, S. J. Organomet. Chem. 2003, 687, 39. (h) Ateşin, T. A.; Ateşin, A. C.; Skugrud, K.; Jones, W. D. Inorg. Chem. 2008, 47, 4596. (i) Grochowski, M. R.; Li, T.; Brennessel, W. W.; Jones, W. D. J. Am. Chem. Soc. 2010, 132, 12412. (j) Grieb, A. L.; Merola, J. S. J. Organomet. Chem. 2012, 713, 163.

(4) Inami, T.; Takahashi, T.; Kurahashi, T.; Matsubara, S. J. Am. Chem. Soc. 2019, 141, 12541.

(5) (a) Wilhelm, M.; Schmidt, P. Helv. Chim. Acta 1970, 53, 1697. (b) Kaupp, G.; Gründken, E.; Matthies, D. Chem. Ber. 1986, 119, 3109. (c) Hofmann, H.; Fischer, H.; Bremer, M. Chem. Ber. 1987, 120, 2087. (d) Cabarrocas, G.; Rafel, S.; Ventura, M.; Villalgordo, J. M. Synlett 2000, 595. (e) Cabarrocas, G.; Ventura, M.; Maestro, M.; Mahía, J.; Villalgordo, J. M. Tetrahedron: Asymmetry 2001, 12, 1851. (f) Chanteau, F.; Didier, B.; Dondy, B.; Doussot, P.; Plantier-Royon, R.; Portella, C. Eur. J. Org. Chem. 2004, 1444. (g) Hayakawa, S.; Matsuo, K.; Yamada, H.; Fukui, N.; Shinokubo, H. J. Am. Chem. Soc. 2020, 142, 11663.
(6) Kassaee, M. Z.; Musavi, S. M.; Momeni, M. R.; Shakib, F. A.; Ghambarian, M. J. Mol. Struct.: THEOCHEM 2008, 861, 117.

(7) CCDC 1037880 contains the supplementary crystallographic data for compound $\mathbf{5 a}$ (dimer). The data can be obtained free of charge from The Cambridge Crystallographic Data Centre via www.ccdc.cam.ac.uk/structures.

(8) 3,4-Diisopropyl-2-(trifluoromethyl)quinoline (4aa): Typical Procedure

The reaction was performed in a $5 \mathrm{~mL}$ sealed tube equipped with a Teflon-coated magnetic stirrer bar. Benzothiazole 1a $(0.20 \mathrm{mmol})$ and alkyne $\mathbf{2 a}(0.40 \mathrm{mmol} ; 2.0$ equiv) were added to a solution of bis(1,5-cyclooctadiene)nickel $(5.5 \mathrm{mg}, 0.02$ $\mathrm{mmol}, 10 \mathrm{~mol} \%$ ) and $\operatorname{IPr}(15.6 \mathrm{mg}, 0.04 \mathrm{mmol}, 20 \mathrm{~mol} \%)$ in hexane $(0.3 \mathrm{~mL})$ in a dry box. The sealed tube was removed from the dry box, and the mixture was stirred at $\mathrm{rt}$ for $12 \mathrm{~h}$ then heated at $80{ }^{\circ} \mathrm{C}$ for $3 \mathrm{~h}$. The resulting mixture was cooled to rt, filtered through a pad of silica gel, and concentrated in vacuo. The residue was purified by flash column chromatography [silica gel, hexane-EtOAc $(20: 1)$ ] to give a white solid; yield: $53.1 \mathrm{mg}$ (94\%); $\mathrm{mp} 55-57^{\circ} \mathrm{C}$.

IR (KBr): 2965, 2872, 1364, 1302, 1177, 1126, 1065, 768, 740 $\mathrm{cm}^{-1} .{ }^{1} \mathrm{H}$ NMR $\left(500 \mathrm{MHx}, \mathrm{CDCl}_{3}\right): \delta=8.15(\mathrm{dd}, J=8.5,1.0 \mathrm{~Hz}, 1 \mathrm{H}$, Ar), 8.02 (dd, $J=8.5,1.0 \mathrm{~Hz}, 1 \mathrm{H}$; Ar), 7.73-7.69 (m, $1 \mathrm{H}, \mathrm{Ar})$, 7.65-7.62 (m, $1 \mathrm{H}, \mathrm{Ar}), 3.12-3.09$ (m, $\left.2 \mathrm{H}, \mathrm{CH}_{2} \mathrm{Et}\right), 2.90-2.87$ (m, $\left.2 \mathrm{H}, \mathrm{CH}_{2} \mathrm{Et}\right), 1.73-1.60\left(\mathrm{~m}, 4 \mathrm{H}, 2 \mathrm{CH}_{2} \mathrm{CH}_{2} \mathrm{CH}_{3}\right), 1.15(\mathrm{t}, J=7.5 \mathrm{~Hz}, 3$ $\left.\mathrm{H}, \mathrm{CH}_{3}\right), 1.11\left(\mathrm{t}, J=7.5 \mathrm{~Hz}, 3 \mathrm{H}, \mathrm{CH}_{3}\right) .{ }^{13} \mathrm{C}$ NMR $(125.7 \mathrm{MHz}$, $\left.\mathrm{CDCl}_{3}\right): \delta=149.3,146.2(\mathrm{q}, J=31 \mathrm{~Hz}), 145.0,130.9,130.4,129.1$, 128.2, 123.6, $122.4(\mathrm{q}, J=275 \mathrm{~Hz}), 30.5(\mathrm{~d}, J=2.4 \mathrm{~Hz}), 30.2,24.9$, $24.3,14.80,14.78 .{ }^{19} \mathrm{~F}$ NMR $\left(188 \mathrm{~Hz}, \mathrm{CDCl}_{3}\right): \delta=-64.1$. HRMS (ESI+): $m / z[M+H]^{+}$calcd for $\mathrm{C}_{16} \mathrm{H}_{19} \mathrm{~F}_{3} \mathrm{~N}$ : 282.1464; found: 282.1460. 